\title{
Intercellular transfer of mitochondrial DNA carrying metastasis-enhancing pathogenic mutations from high- to low-metastatic tumor cells and stromal cells via extracellular vesicles
}

\author{
Keizo Takenaga ${ }^{*}$, Nobuko Koshikawa and Hiroki Nagase
}

\begin{abstract}
Background: Mitochondrial DNA (mtDNA) carrying certain pathogenic mutations or single nucleotide variants (SNVs) enhances the invasion and metastasis of tumor cells, and some of these mutations are homoplasmic in tumor cells and even in tumor tissues. On the other hand, intercellular transfer of mitochondria and cellular components via extracellular vesicles (EVs) and tunneling nanotubes (TNTs) has recently attracted intense attention in terms of cell-to-cell communication in the tumor microenvironment. It remains unclear whether metastasisenhancing pathogenic mutant mtDNA in tumor cells is intercellularly transferred between tumor cells and stromal cells. In this study, we investigated whether mtDNA with the NADH dehydrogenase subunit 6 (ND6) G13997A pathogenic mutation in highly metastatic cells can be horizontally transferred to low-metastatic cells and stromal cells in the tumor microenvironment.
\end{abstract}

Results: When MitoTracker Deep Red-labeled high-metastatic Lewis lung carcinoma A11 cells carrying the ND6 G13997A mtDNA mutation were cocultured with CellLight mitochondria-GFP-labeled low-metastatic P29 cells harboring wild-type mtDNA, bidirectional transfer of red-and green-colored vesicles, probably mitochondria-related EVs, was observed in a time-dependent manner. Similarly, intercellular transfer of mitochondria-related EVs occurred between A11 cells and a-smooth muscle actin (a-SMA)-positive cancer-associated fibroblasts (CAFs, WA-mFib), macrophages (RAW264.7) and cytotoxic T cells (CTLL-2). Intercellular transfer was suppressed by inhibitors of EV release. The large and small EV fractions (L-EV and S-EV, respectively) prepared from the conditioned medium by differential ultracentrifugation both were found to contain mtDNA, although only S-EVs were efficiently incorporated into the cells. Several subpopulations had evidence of LC3-II and contained degenerated mitochondrial components in the S-EV fraction, signaling to the existence of autophagy-related S-EVs. Interestingly, the S-EV fraction contained a MitoTrackerpositive subpopulation, which was inhibited by the respiration inhibitor antimycin $A$, indicating the presence of mitochondria with membrane potential. It was also demonstrated that mtDNA was transferred into mtDNA-less $p^{0}$ cells after coculture with the S-EV fraction. In syngeneic mouse subcutaneous tumors formed by a mixture of A11 and P29 cells, the mitochondria-related EVs released from A11 cells reached distantly positioned P29 cells and CAFs.

\footnotetext{
* Correspondence: ktakenaga@chiba-cc.jp

Division of Cancer Genetics, Chiba Cancer Center Research Institute, Nitona, Chuoh-ku, Chiba, Japan
}

(c) The Author(s). 2021 Open Access This article is licensed under a Creative Commons Attribution 4.0 International License, which permits use, sharing, adaptation, distribution and reproduction in any medium or format, as long as you give appropriate credit to the original author(s) and the source, provide a link to the Creative Commons licence, and indicate if changes were made. The images or other third party material in this article are included in the article's Creative Commons licence, unless indicated otherwise in a credit line to the material. If material is not included in the article's Creative Commons licence and your intended use is not permitted by statutory regulation or exceeds the permitted use, you will need to obtain permission directly from the copyright holder. To view a copy of this licence, visit http://creativecommons.org/licenses/by/4.0/. The Creative Commons Public Domain Dedication waiver (http://creativecommons.org/publicdomain/zero/1.0/) applies to the data made available in this article, unless otherwise stated in a credit line to the data. 
Conclusions: These results suggest that metastasis-enhancing pathogenic mtDNA derived from metastatic tumor cells is transferred to low-metastatic tumor cells and stromal cells via S-EVs in vitro and in the tumor microenvironment, inferring a novel mechanism of enhancement of metastatic potential during tumor progression.

Keywords: Mitochondria, Mitochondrial DNA, Mutation, Extracellular vesicles, Intercellular transfer, Lung cancer, Tumor microenvironment, Metastasis

\section{Background}

We and others previously showed that certain mitochondrial DNA (mtDNA) somatic mutations or single nucleotide variants (SNVs) enhanced the invasion and metastasis of mouse and human cell lines, e.g., NADH dehydrogenase subunit 6 (ND6) G13997A in Lewis lung carcinoma cells [1, 2], ND6 13885insC in mouse fibrosarcoma cells $[1,2], N D 3$ G10398A and $t R N A^{\operatorname{Leu}(C U N)}$ A12308G in human breast cancer cells [3, 4], ATP6 T8993G and ND3 A10398G in human prostate cancer cells $[5,6], t R N A^{\operatorname{Leu}(C U N)}$ A3243T in human osteosarcoma cells [7] and 12S rRNA (RNR1) G709A in human hepatocellular carcinoma [8]. Furthermore, the frequency of predicted pathogenic mtDNA mutations was significantly correlated with distant metastasis in patients with non-small cell lung carcinoma (NSCLC) and colon cancers [2]. Although the mechanisms underlying the enhancement of metastasis have not been fully elucidated, it has been demonstrated that pathogenic mtDNA mutations or SNVs confer apoptotic resistance against various stresses to tumor cells $[1,3,4,9,10]$ and increase the expression of various nuclear-encoded metastasis-related genes, such as antiapoptotic $\mathrm{Mcl}-1, \mathrm{~K}$ ras, $c$-myc, and hypoxia-inducible factor- $1 \alpha(H I F-1 \alpha)$, compared to their counterparts with wild-type mtDNA $[1,2]$. Interestingly, although somatic mutations usually show heteroplasmy, some of the somatic mutations or SNVs in tumor cells and even in tumor tissues of a variety of tumors are homoplasmic [2, 11-15]. This phenomenon could be simply due to a low percentage of stromal cells that are supposed to have wild-type mtDNA in the tumor tissues analyzed, but it is possible that stromal cells also have the same mutant mtDNA as tumor cells. This possibility has never been tested.

Recent studies have highlighted intercellular communication between tumor cells and stromal cells in the tumor microenvironment via extracellular vesicles (EVs) and tunneling nanotubes (TNTs) [16-19]. EVs are mainly comprised of heterogeneous cell-derived membranous structures and across three subclasses: small EVs (S-EVs), large EVs (L-EVs) and an intermediate group known as small to large EVs [20]. Typical S-EVs are exosomes that are 50 - to $150-\mathrm{nm}$, characterized by tetraspanins CD9, CD63 and CD81, and contain mitochondrial cargo and other cellular components. L-EVs include microvesicles that are 100- to $1000-\mathrm{nm}$, featured by a high content of annexin A1, and encapsulate mitochondria and other components $[19,20]$. Autophagic EVs belong to the small to larger EV subclass and have the characteristics of expressing microtubule-associated protein 1 light chain 3 (LC3) [20]. In addition, mitovesicles are a recently identified novel population of EVs of mitochondrial origin that contain abundant mitochondrial markers and reflect the alteration of pathophysiological processes where mitochondrial dysfunction occurs and are much smaller than native mitochondria [21]. TNTs are actin-based direct cell-to-cell communication channels that serve to transfer a variety of molecules and organelles, including mitochondria and exosomes, which are thought to be the main delivery route to transfer intact mitochondria in solid tumors $[18,22,23]$. EV- and TNT-mediated cell-to-cell communication between cancer cells and stromal cells, such as bone marrow-derived mesenchymal stem cells, fibroblasts and endothelial cells, is reported to play roles in alterations in cancer cell bioenergetics, chemoresistance, invasion and metastasis [16-18, 22, 23]. However, because a variety of cellular components, such as cellular proteins, lipids, mRNAs and microRNAs, are transferred via EVs and TNTs from stromal cells to tumor cells and vice versa $[19,23]$, the exact functional roles of transferred mitochondria, particularly tumor-derived mutant mtDNAs, remain unknown. Furthermore, because mitochondria with pathogenic mutant mtDNAs are somewhat dysfunctional, they are considered to be subjected to degradation by mitophagy, a mitochondrial quality control mechanism [24]. At present, it is unclear whether intact circular pathogenic mutant mtDNAs are included in EVs and whether they are intercellularly transferred between tumor cells and stromal cells, including cancer-associated fibroblasts (CAFs), tumorassociated macrophages (TAMs) and immune cells, in the tumor microenvironment.

In the present study, we investigated whether mtDNAs harboring a metastasis-enhancing pathogenic mutation in highly metastatic cancer cells are transferred to lowmetastatic cells and stromal cells in vitro and in the tumor microenvironment. The results showed that they are transferred to low-metastatic cells and stromal cells via certain subpopulations of S-EVs, indicating that selection 
and prevalence of transferred mtDNA during tumor growth and progression could enhance the metastatic ability of low-metastatic tumor cells and alter the phenotypes of stromal cells in the tumor microenvironment.

\section{Results \\ Bidirectional intercellular transfer of mitochondria-related vesicles}

To examine whether mtDNA is intracellularly transferred, we labeled the mitochondria of mouse lung carcinoma P29 cells harboring wild-type mtDNA with MitoTracker Deep Red (P29-MTDR) and those of A11 cells carrying G13997A mtDNA with CellLight mitochondria-GFP (A11-mtGFP) and cocultured them for $24 \mathrm{~h}$. As a consequence, we found that individual cells had both red- and green-colored vesicles within the cells, as assessed by confocal laser microscopy (Fig. 1a). The same outcome was obtained in cocultures of P29-mtGFP cells and A11MTDR cells (Fig. S1). These results indicated that mitochondria or mitochondrial-related vesicles were transferred from A11 cells to P29 cells and vice versa. In addition, when EGFP-expressing P29 cells (EGFP-P29) were cocultured with A11-MTDR cells, red-colored vesicles were detected in the cytoplasm of noncontacting EGFP-P29 cells (Fig. 1b). Notably, the red-colored vesicles were unevenly localized in EGFP-P29 cells, excluding the possibility that the vesicles were merely attached to the outside of EGFP-P29 cells. Mitochondria-related vesicle transfer in the coculture of P29-mtGFP and A11-MTDR cells was detected as early as $4 \mathrm{~h}$ after the start of coculture (Fig. 1c). Furthermore, when A11-MTDR cells were cocultured with mtGFP-labeled $\alpha$-smooth muscle actin ( $\alpha$-SMA)-positive CAFs (WA-mFib-mtGFP), macrophages (RAW264.7-mtGFP) or cytotoxic $\mathrm{T}$ cells (CTLL-2mtGFP), we obtained similar results, although the degree of intercellular transfer was lower in the A11-WA-mFib coculture than in other cocultures (Fig. 2), perhaps due to the weak ability of WA-mFib cells to take up and release mitochondria-related vesicles. Bidirectional vesicle transfer was barely observed in A11 cells-normal fibroblasts (MEF) coculture (Fig. S2). Together, these results indicated that mitochondria or mitochondrial components were transferred not only between tumor cells but also between tumor cells and stromal cells.

\section{EVs contain mitochondrial components and mtDNA}

To determine the mechanisms underlying intercellular mitochondria-related vesicle transfer, we carried out coculture of P29 and A11 cells in the presence or absence of the EV secretion inhibitors GW4869 and tipifarnib $[25,26]$. The results showed that both inhibitors suppressed, although not completely, intercellular transfer (Fig. 3), suggesting the involvement of EVs released from the cells. Close observation of the coculture revealed the presence of both green- and red-colored vesicles in the areas where no cells existed (Fig. S3). Then, we prepared L-EV and S-EV fractions from A11 and P29 cell culture medium by differential ultracentrifugation (Fig. 4a). PCR analysis using ND6 primers showed that both L-EV and S-EV fractions contained evidence of mtDNA (Fig. 4b); when these EV preparations were added to A11 or P29 cells, we found L-EVs to merely attached on the surface of cell membrane while cells actively incorporated S-EVs (Fig. 4c) in a manner that fairly resembled vesicle transfer images in the coculture (Fig. 1), prompting us to focus our investigation on S-EVs. A11 S-EVs showed a size range between approximately 70 and $300 \mathrm{~nm}$ (Fig. 5a) and showed the appearance of EVs, as demonstrated by negative-stain transmission electron microscopy (TEM) (Fig. 5b). The microvesicle marker protein annexin A1 in both P29 and A11 S-EV fractions (Fig. 5c) were absent in immunoblots. Among the classical exosome marker proteins, CD9 was detected in both P29 and A11 S-EV fractions, yet we found neither S-EV fraction had any enrichment of CD63; CD81 was observed in only the P29 S-EV fraction (Fig. 5c). Neither was glyceraldehyde-3-phosphate dehydrogenase (GAPD $\mathrm{H})$, a protein abundant in the cytosol and the nonvesicular material in S-EV preparations [20]; the absence of GAPDH confirmed the lack of intracellular contaminants and non-vascular fractions in our findings. Of note, LC3, particularly LC3-II, was detected in both P29 and A11 S-EV fractions, indicating the presence of autophagy-related EV subpopulation [20]. The amount of LC3-II in P29 S-EV fraction was lower than the A11 S-EV fraction. We observed the presence of $\beta$-Actin in both S-EV fractions, while the protein had been reported to be rich in all types of EVs except exosomes [20] (Fig. 5c); the amount was relatively lower in P29 group. In A11 S-EV preparations, we detected traces of certain mitochondrial proteins, such as the inner membrane protein Complex III core 1 (CIII Core 1), the outer membrane proteins Porin 1 and 2, and the intermembrane protein Cytochrome c (Cyt c), although the relative abundance of individual protein markedly differed from that of intact mitochondria. The outer membrane protein Complex $\mathrm{Va}(\mathrm{CVa})$ and the matrix protein Cyclophilin D (CypD) were not seen (Fig. 6a). CryoTEM revealed double membrane and electron lucent structures in some population of A11 S-EVs (Fig. 6b); these double membrane structures were either mitochondrial membranes that lacked distinct cristae, or nuclear membranes. Since we detected mitochondrial membrane proteins but not nuclear lamins in the S-EV preparations (Fig. 5c), such double-membraned structures were more likely to be mitochondrial in origin. These results suggested that A11 S-EV fraction contained a subpopulation with degenerated mitochondrial 


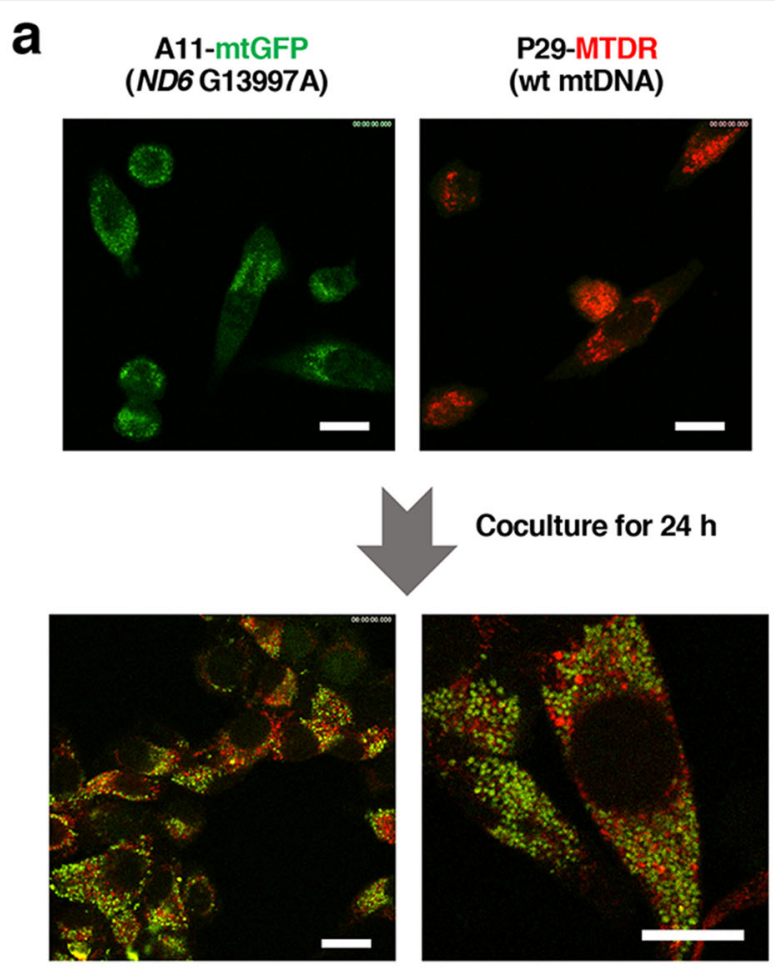

b

A11-MTDR + EGFP-P29

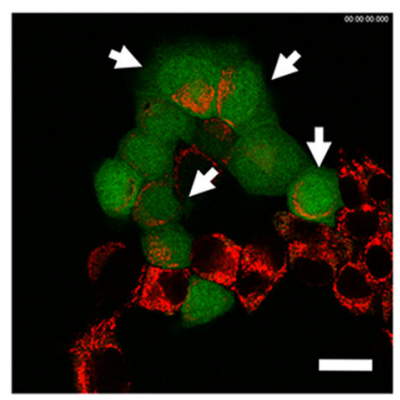

C

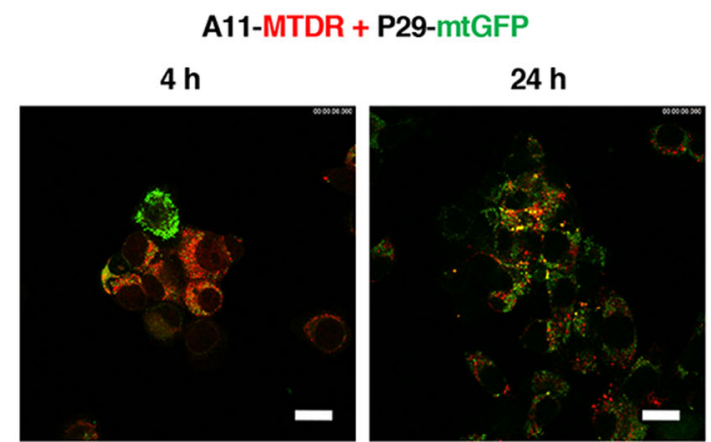

Fig. 1 Intercellular transfer of mitochondria-related vesicles. (a) Intercellular transfer of mitochondria-related vesicles between A11 and P29 cells. mtGFP-labeled A11 cells (A11-mtGFP) and MTDR-labeled P29 cells (P29-MTDR) were cocultured for $24 \mathrm{~h}$ and observed under a laser confocal microscope. Scale bars: $20 \mu \mathrm{m}$. (b) Intercellular transfer of mitochondria-related vesicles of A11 cells to P29 cells expressing EGFP. MTDR-labeled A11 cells (A11-MTDR) were cocultured with EGFP-P29 cells for $24 \mathrm{~h}$. Arrows indicate EGFP-P29 cells harboring red-colored mitochondrial-related vesicles. Scale bars: $20 \mu \mathrm{m}$. (c) Time course of intercellular transfer of mitochondria-related vesicles. MTDR-labeled A11 cells (A11-MTDR) were cocultured with mtGFP-labeled P29 cells (P29-mtGFP) for $4 \mathrm{~h}$ and $24 \mathrm{~h}$. The cells were observed under a laser confocal microscope. Scale bars: $20 \mu \mathrm{m}$

fragments. Interestingly, however, some of the S-EVs isolated from the conditioned medium of MitoTracker Red-stained A11 and P29 cells emitted red fluorescence (Fig. 6c). Furthermore, when naïve A11 S-EVs were incubated with MitoTracker Red, some but not all S-EVs accumulated the dye, which was suppressed by antimycin A, an inhibitor of cellular respiration (Fig. 6d).

We next examined whether full-length mtDNA existed in A11 S-EVs by PCR using primer pairs to amplify various locations of mtDNA [D-loop hypervariable region
(HVR), ND1, COI, ND4 and ND6] (Fig. 7a). As a result, PCR analysis revealed the presence of all other genes in A11 S-EV preparation (Fig. 7b), suggesting the existence of full-length mtDNA. A11 S-EV preparation contained mtDNA with the G13997A mutation, as demonstrated by PCR-RFLP using mismatched primers that create the AflII restriction site (Fig. 7c). After isolating MEF S-EVs and EVs from normal C57BL/6 mouse serum using a commercially available exosome isolation reagent, we found the vesicles to contain a very small amount of 


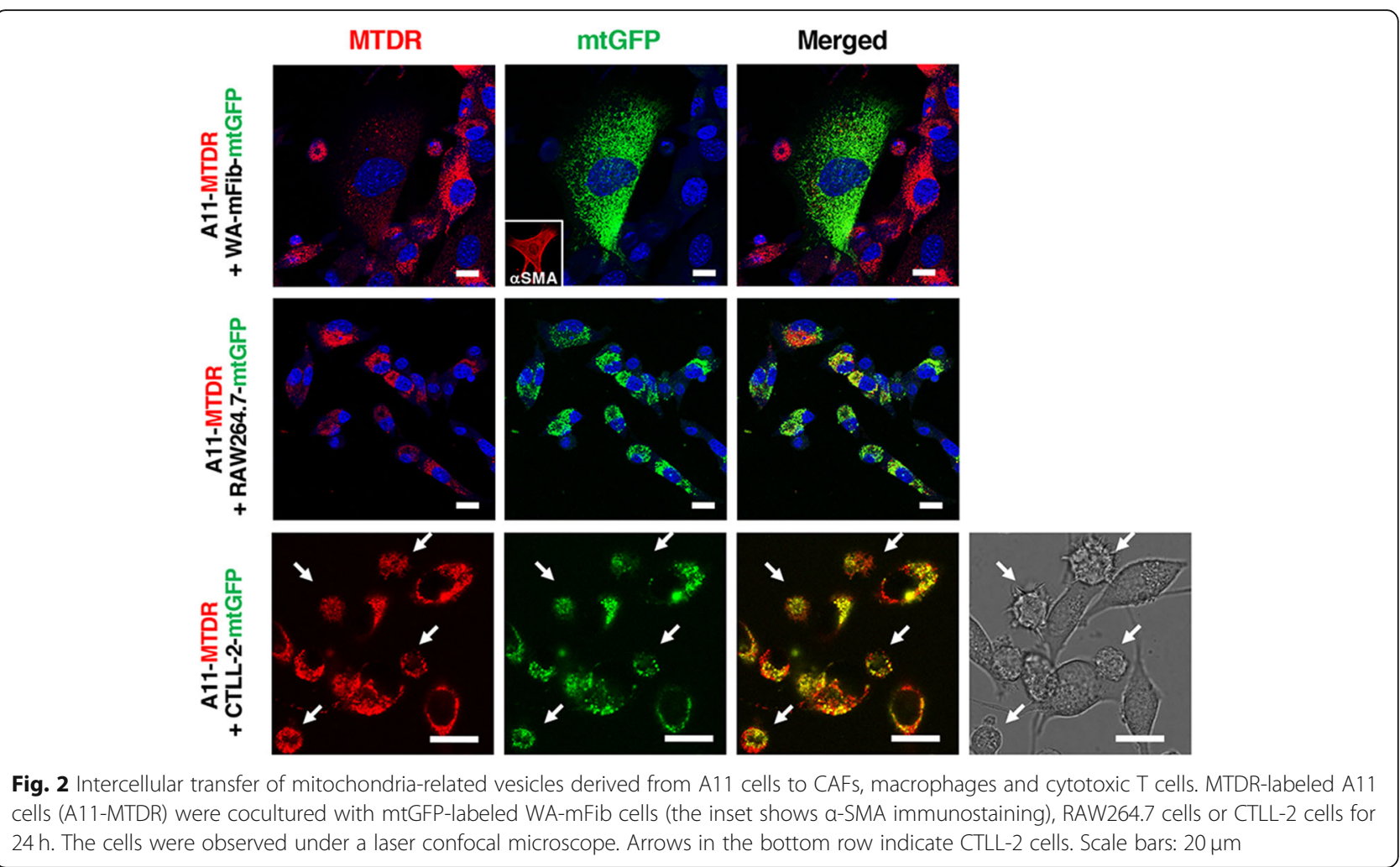

mtDNA (Fig. 7d), indicating that normal cells could have ejected small amounts of mtDNA-containing EVs compared to tumor cells. For reference, we also provided data on the release of mtDNA-containing S-EVs from human cancer cell lines (HeLa, A549, DLD-1 and MIAPaCa-2) (Fig. S4).

\section{Transfer of mtDNA via S-EVs to $\rho^{0}$ cells}

When S-EVs prepared from the cell culture medium of A11-MTDR cells labeled with PHK67 (thus bicolor EVs) were added to P29 cells and cultured for $24 \mathrm{~h}$, they were detected in the cells (Fig. S5). To verify whether mtDNA in S-EVs is actually transferred to recipient cells, we employed $\rho^{0} \mathrm{P} 29$ cells because transferred mtDNA can be easily detected in these cells (Fig. 8a). We incubated S-EVs (equivalent to $2 \mu \mathrm{g}$ protein) from P29 and A11 cells with $\rho^{0} \mathrm{P} 29$ cells for 2 days in the presence or absence of the EV-Entry System. After incubation, the cells were treated with trypsin/EDTA for $10 \mathrm{~min}$, washed extensively with PBS, and then subjected to DNA extraction. By PCR of the ND1 gene, we detected mtDNA in $\rho^{0} \mathrm{P} 29$ cells that were incubated with P29 S-EV and A11 $\mathrm{S}$-EV fractions. However, we needed to use the EV-Entry System to clearly detect the transferred mtDNA (Fig. $8 b)$, suggesting that $\rho^{0} \mathrm{P} 29$ cells have a weak ability to incorporate exogenously added S-EVs. In contrast, for reference, when we incubated $\rho^{0} \mathrm{HeLa}$ cells with HeLa SEVs, we detected mtDNA in $\rho^{0} \mathrm{HeLa}$ cells even in the absence of EV-Entry System (Fig. S6). These results indicate that mtDNA in S-EVs can be transferred to recipient cells in a cell-selective manner.

Intercellular transfer of mitochondria-derived vesicles in the tumor microenvironment

Finally, to investigate whether the observed cell-to-cell EV transfer occurs in the tumor microenvironment in a syngeneic mouse model, we intratumorally injected homografted MitoBright LT Red-labeled A11 cells (A11Mito LT Red) into syngeneic EGFP-P29 tumors. Three days after the injection, tumors were resected and embedded in OCT compounds for preparing cryosections. Because of weak EGFP fluorescence, we immunostained cryosections (7- $\mu \mathrm{m}$ thick) with rabbit anti-GFP antibody followed by AF488-conjugated goat anti-rabbit IgG to clearly identify EGFP-P29 cells. Close examinations of the sections revealed that red-colored mitochondriarelated vesicles were detected away from A11-Mito LT Red cells and localized in EGFP-P29 cells via a nonpassive transportation method (Fig. 9a, bottom, rightmost panel). In another experiment, we injected A11-Mito LT Red cells into P29 tumors. Immunostaining of cryosections for $\alpha$-SMA showed red-colored vesicles in $\alpha$-SMApositive CAFs (Fig. 9b, bottom, dotted squares, rightmost panel). These results suggest the occurrence of intracellular mtDNA transfer in the tumor 

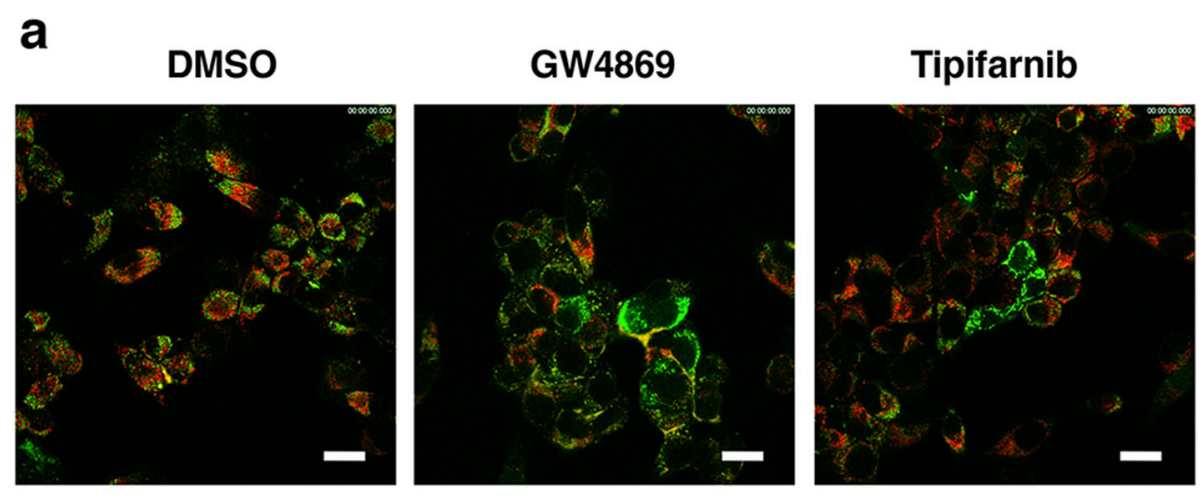

b

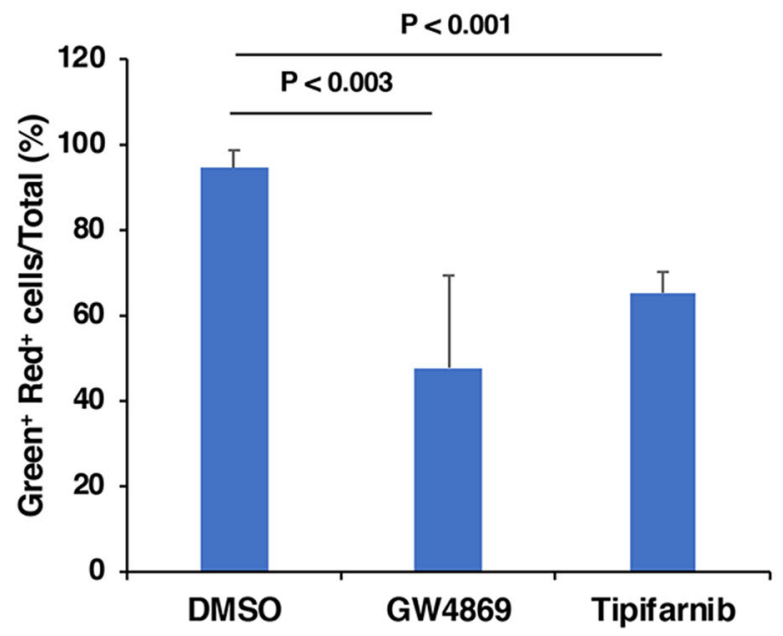

Fig. 3 Effect of GW4869 and tipifarnib on intercellular transfer of mitochondria-related vesicles. (a) mtGFP-labeled A11 cells (A11-mtGFP) and MTDR-labeled P29 cells (P29-MTDR) were cocultured in the presence or absence of $10 \mu \mathrm{M}$ GW4869 or $1 \mu \mathrm{M}$ tipifarnib for $24 \mathrm{~h}$ and observed under a laser confocal microscope. Scale bars: $20 \mu \mathrm{m}$. (b) Semi-quantification of intercellular transfer of mitochondria-related vesicles. The number of green- and red-double positive cells per total number of cells in the images ( $n=4,5$ and 6 images for DMSO, GW4869 and Tipifarnib group, respectively) was counted

microenvironment, although the exact subtype of EVs involved in the transfer remained to be clarified.

\section{Discussion}

The present results showed that deteriorated mitochondria containing metastasis-prone G13997A mtDNA of A11 cells was encapsulated in a certain subpopulation of S-EVs and released extracellularly. Several recent studies indicate that cells routinely release mitochondria extracellularly via EVs [27-29]; for instance, cardiomyocytes release subcellular LC3-positive "exophers" $(3.5 \pm 0.1 \mu \mathrm{m}$ in size) in order to shuttle defective mitochondria for elimination [29]. The extracellular release of a particular form of naked mitochondria $(\sim 500 \mathrm{~nm}$ in size) is also said to be an alternative mitochondrial quality control mechanism [30]. The S-EVs in this study may be different from other S-EVs in the literature, for example recently identified mitovesicles that are both electron dense, and rich in mitochondrial proteins [21]; typical exosomes also do not contain double-stranded DNA [20]. Despite the lack of direct evidence, the process called "secretary autophagy" in which LC3-positive double membrane autophagosomes are released extracellularly without fusion with lysosomes [31], is likely the source of vesicles found in A11 S-EVs. Dysfunctional mitochondria are known to undergo mitophagy [24]. Because the G13997A mutation lowers Complex I activity, A11 mitochondria are likely to be susceptible to oxidative stress [1] and as a result prone to a greater amount of damage and degradation by mitophagy compared to those in P29 cells. It is likely that certain extracellularly released mitophagosomes can bypass fusion with lysosomes, as (1) A11 S-EVs preparation contain subpopulations harboring degenerated mitochondrial components, (2) P29 S-EV preparation contain a lower level of LC3-II than A11 S-EVs, and (3) P29 and MEF S-EVs contain lower quantities of mtDNA compared to A11 S-EVs; in this sense, we can refer to the process of extracellular release of degenerated mitochondria as "secretary mitophagy/autophagy". Additionally, while some S-EV subpopulations still contained functioning mitochondria with detectable membrane potential, this was likely a 
a
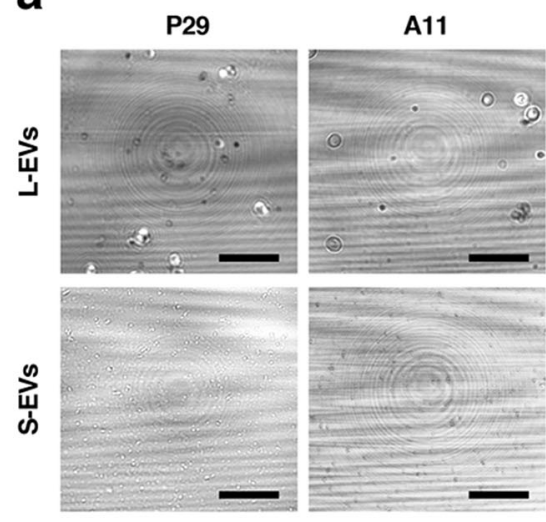

b

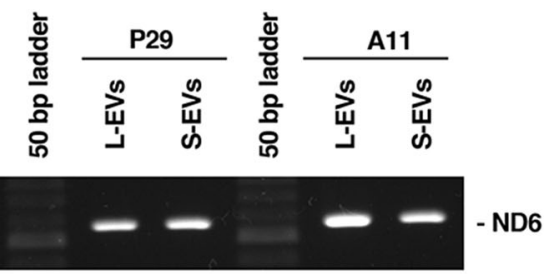

C A11 + PKH67-P29 L-EVs

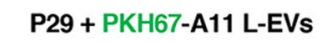

P29 + PKH67-A11 S-EVs
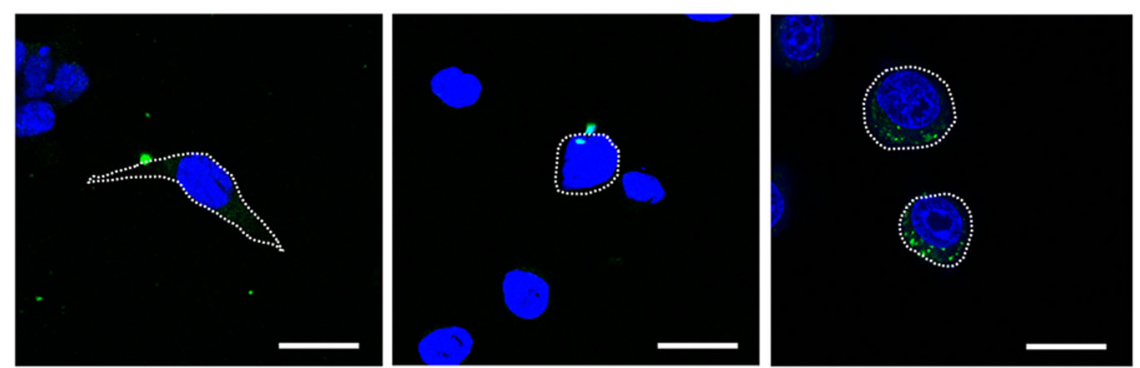

Fig. $4 \mathrm{~L}$-EVs and S-EVs isolated from the conditioned medium of P29 and A11 cells. (a) Reflection images of L-EVs and S-EVs. Scale bars: $10 \mu m$. (b) PCR analysis of the presence of mtDNA ND6 gene in L-EVs and S-EVs. (c) Localization of L-EVs and S-EVs added to P29 or A11 cells. P29 or A11 cells were incubated with PKH67-labeled L-EVs or S-EVs for $24 \mathrm{~h}$ and observed under a laser confocal microscope. Dashed lines represent the outline of the cells. Scale bars: $20 \mu \mathrm{m}$

reflection of transient remnants of respiratory activity from degenerated mitochondria in freshly prepared SEVs. While one may question the physiological relevance of other cells incorporating wasted mitochondria, it is only presumable that mtDNA in such mitochondria still contained critical role, yet to be fully elucidated, inside the recipient cells.

This study demonstrated that G13997A mtDNA was horizontally transferred to P29 cells and stromal cells in vitro via S-EVs. Unfortunately, however, we still have not been able to demonstrate the physiological relevance of G13997A mtDNA transfer, i.e., changes in metastatic potential and apoptosis resistance of P29 cells, because the copy number of G13997A mtDNA did not substantially increase in P29 cells during approximately two months of culture after a single exposure of the cells to A11 S-EVs (data not shown). As in the cases of mitochondrial diseases, a critical threshold of the mutant/ wild-type mtDNA ratio (heteroplasmy) must be exceeded before the pathogenic effect of the mutant mtDNA becomes apparent; the threshold is generally thought to be between 60 and $80 \%$ [32]. Therefore, we need to wait until the heteroplasmy level of G13997A
mtDNA is high to investigate the consequence of mtDNA transfer, although no one knows how long is required. However, we believe that pathogenic mtDNA mutants become prevalent in tumor and stromal cells, either by positive selection or by chance [12, 14], which is supported by the fact that a pathogenic mtDNA somatic mutation that must have occurred in a mtDNA molecule among several hundreds of mtDNA molecules in a cell is often homoplasmic in tumor cells [2, 11-15]. Considering that tumor cells are continuously exposed to EVs released from other cells in the tumor microenvironment, we may need to expose P29 cells to A11 S-EVs several times in vitro to increase G13997A mtDNA copy number, thereby enabling the study of biological relevance of the G13997A mtDNA transfer. To our knowledge, the mtDNA mutation status in stromal cells in cancer tissues has never been investigated, and little is known about how it affects the activity of CAFs, TAMs and effector $\mathrm{T}$ cells. The prevalence of pathogenic mutant mtDNA derived from tumor cells in stromal cells may suppress mitochondrial respiration and results in a switch to a more glycolytic phenotype, which may cause CAFs to provide high-energy metabolites such as 
a

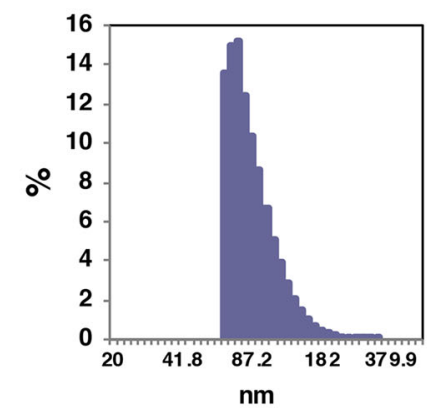

b

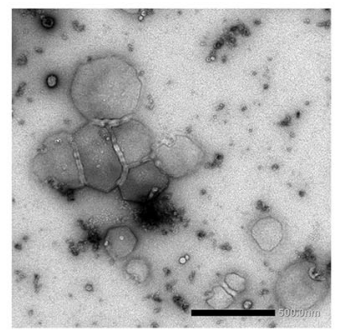

C
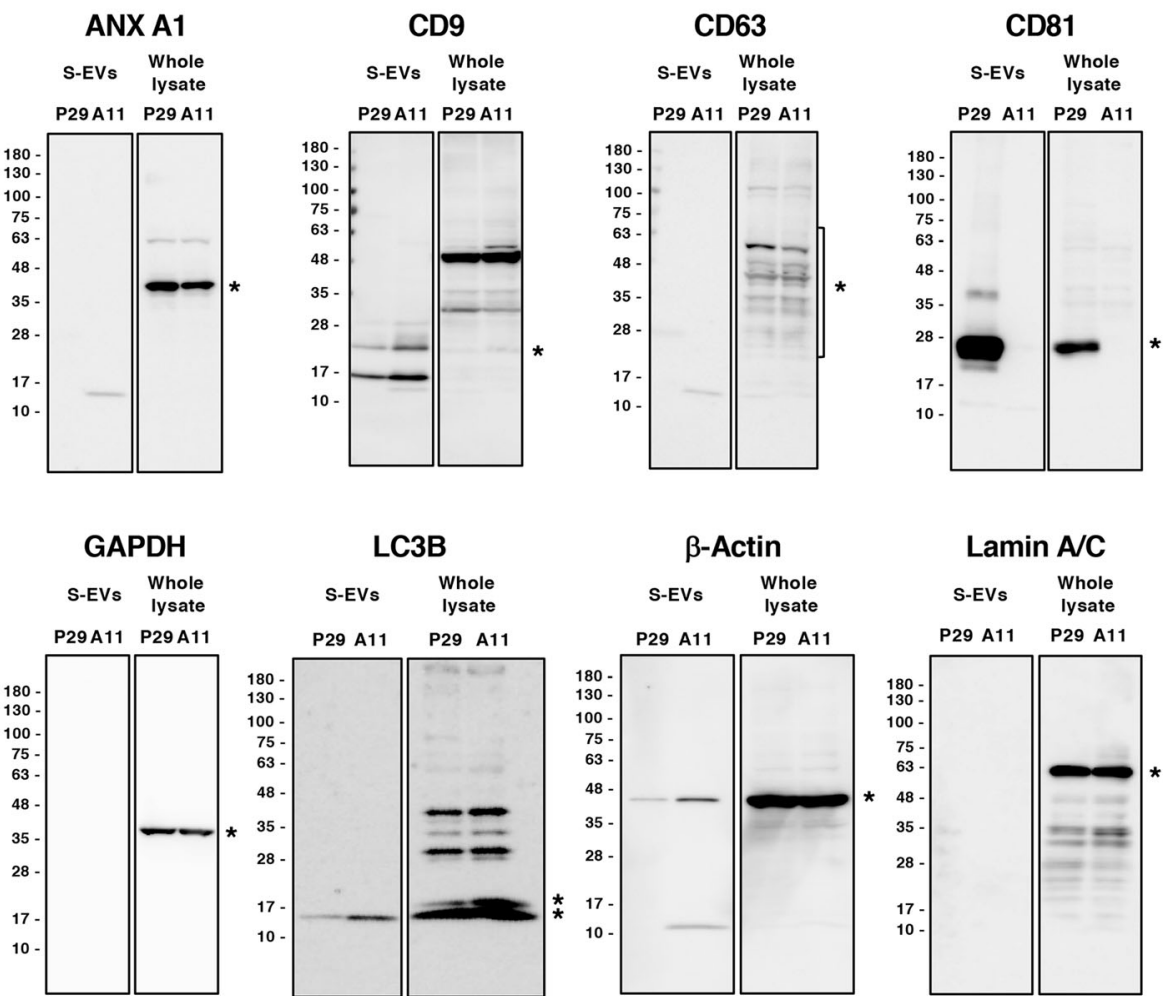

Fig. 5 Characterization of S-EVs isolated from the conditioned medium of A11 cells. (a) A percent bar plot showing the distribution of particle diameter of A11 S-EVs. (b) Negative-stain TEM of A11 S-EVs. Bar: $500 \mathrm{~nm}$. (c) Western blot analyses of various proteins in S-EVs isolated from the conditioned medium of P29 and A11 cells. P29 and A11 S-EVs ( $3 \mu$ g proteins) and whole cell lysates of P29 and A11 cells ( $30 \mu g$ proteins) were loaded on the same gel. Asterisks indicate the position of individual protein. In the LC3B immunoblot, the upper and lower asterisks indicate LC3I and LC3-II, respectively. Uncropped Western blots images are shown in Fig. S7

lactate to cancer cells [33] and stimulate $\mathrm{T}$ cell aging $[34,35]$. These changes may enhance the invasion and metastasis of tumor cells. Thus, it is also important to examine the phenotypic changes of CAFs, TAMs and effector T cells caused by G13997A mtDNA transfer, which await investigation in the future. In addition, the mtDNA mutation status in the stroma in tumor tissues may need to be compared with that in tumor cells. Even though tumor-cell derived EVs have been reported to influence multiple aspects of cancer progression including survival, metastasis, angiogenesis and immune system
[36], there are no reports that describe the direct effect of mutant mtDNAs in contrast to our present cell system, which may provide a valuable tool to investigate such issues in the future.

A limitation of the present study may be the absence of concrete evidence that mitochondrial components from A11 cells are actually transferred to P29 cells and CAFs in the tumor microenvironment. To address this, more sophisticated analyses, e.g., intravital microscopy and single cell analysis of the presence of mutant mtDNA in tumor or stromal cells distantly located from 


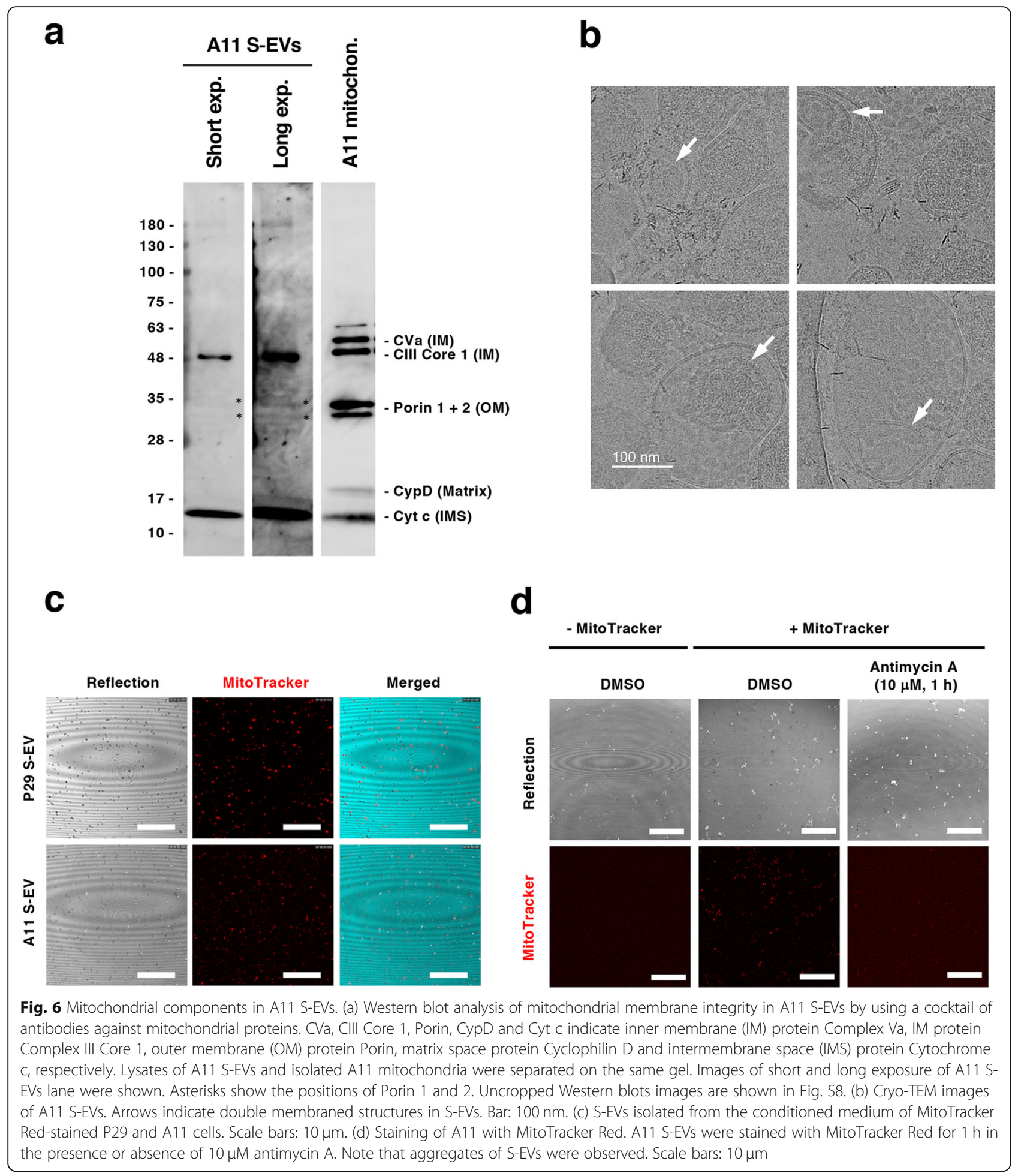

donor tumor cells may be required to demonstrate in vivo mtDNA transfer. Clarification of the exact type of EVs participating in the transfer is also critical, in addition to understanding the involvement of TNTmediated mitochondrial transfer in this experimental setting.
Moreover, mtDNA mutations are known to accumulate during aging, and mitochondria become dysfunctional during aging [37]. Transfer of mutation-accumulated mtDNA in a senescent cell to surrounding cells may stimulate local senescence of tissues. Although we focused on mtDNA transfer in the tumor microenvironment, 
a

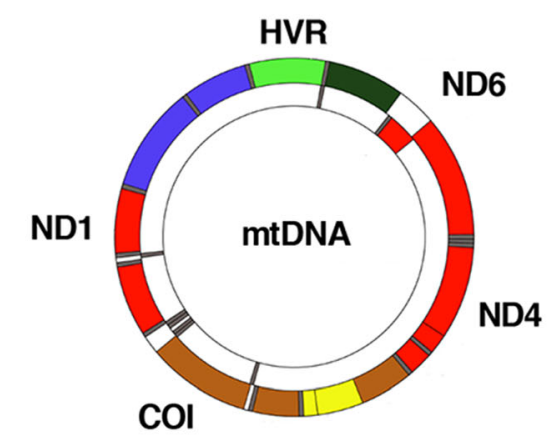

C

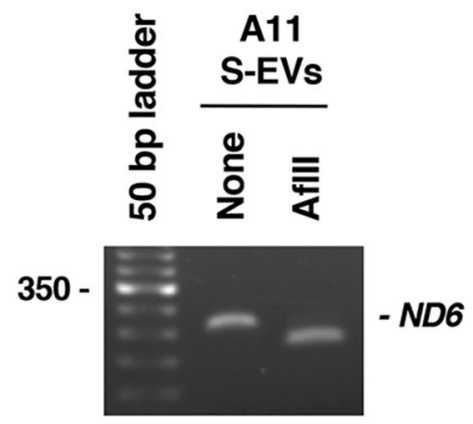

b

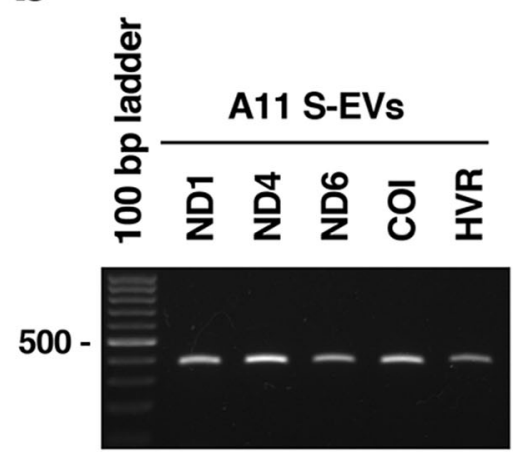

d

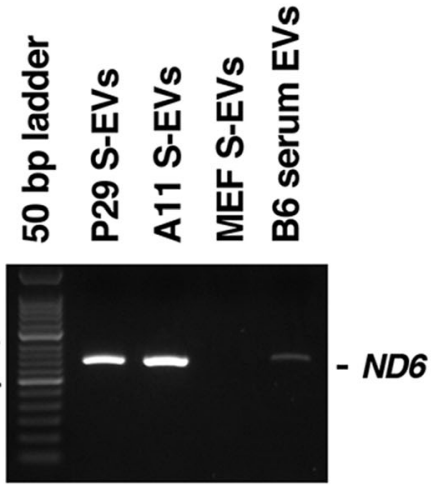

Fig. 7 PCR analysis of the presence of mtDNA in S-EVs. (a) Location of the genes in mtDNA used for PCR analysis. (b) Presence of various mtDNA genes (ND1, ND4, ND6, COI, HVR) in A11 S-EVs. (c) PCR-RFLP analysis of the presence of mtDNA with the ND6 G13997A mutation. The ND6 gene $254 \mathrm{bp}$ fragment amplified by PCR using mismatched primers was digested with Aflll. The primers were designed to generate $223 \mathrm{bp}$ and $31 \mathrm{bp}$ fragments upon Aflll digestion when the G13997A mutation was present. The smaller fragment was not visible. (d) Comparison of the amount of mtDNA in S-EVs isolated from the conditioned medium of P29 cells, A11 cells and MEFs and EVs in B6 serum. Equivalent amounts of EVs ( 90 ng proteins) were used for PCR amplification of the ND6 gene

blocking mtDNA transfer could be a strategy to prevent not only tumor progression but also aging. Further studies are required to unveil the role of mutant mtDNA transfer in these processes.

\section{Conclusions}

In this study, we demonstrated intercellular transfer of metastasis-enhancing mtDNA from high-metastatic lung cancer cells to low-metastatic cells and stromal cells such as CAFs, macrophages and cytotoxic $\mathrm{T}$ cells. Further studies will be focused on the consequence of mutant mtDNA transfer on the metastatic ability of lowmetastatic cells, protumor activity of CAFs and TAMs and tumoricidal activity of cytotoxic T cells.

\section{Methods}

\section{Reagents}

GW4869, a neutral sphingomyelinase inhibitor, and tipifarnib, a farnesyl transferase inhibitor, were obtained from Cayman Chemical (Ann Arbor, MI, USA) and ChemScene LLC (Monmouth, NJ, USA), respectively. MitoTracker Red CMXRos, MitoTracker Deep Red FM (MTDR) and CellLight mitochondria-GFP (mtGFP) were supplied by Thermo Fisher Scientific (Waltham, MA, USA). MitoBright LT Red (MitoB LT Red) was purchased from Dojindo Co., Ltd. (Kumamoto, Japan).

\section{Cells and cell culture}

High-metastatic A11 cells carrying the ND6 G13997A mutation and low-metastatic P29 cells harboring wildtype mtDNA were established from Lewis lung carcinoma $[1,2,10]$. P29 cells expressing EGFP (EGFP-P29) were established by introduction of the pEGFP-N1 expression plasmid followed by G418 selection and cloning. WA-mFib cells, a mouse stromal cell line for human lung small cell carcinoma, and mouse RAW264.7 macrophages (RCB1925 and RCB0535, respectively, from RIKE N BioResource Research Center) [38] were cultured in Dulbecco's modified Eagle's medium (DMEM) 
a

S-EVs (P29, A11)

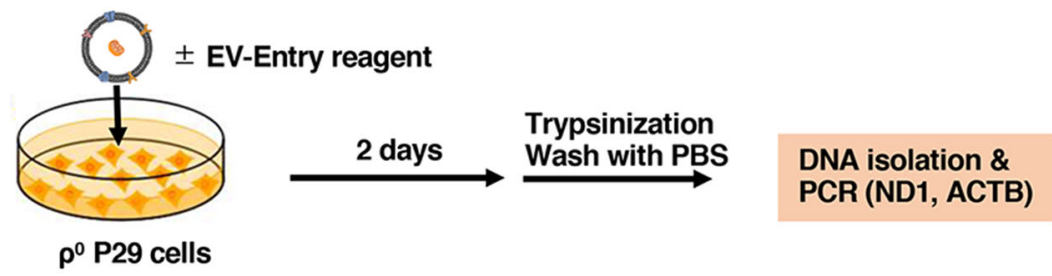

b

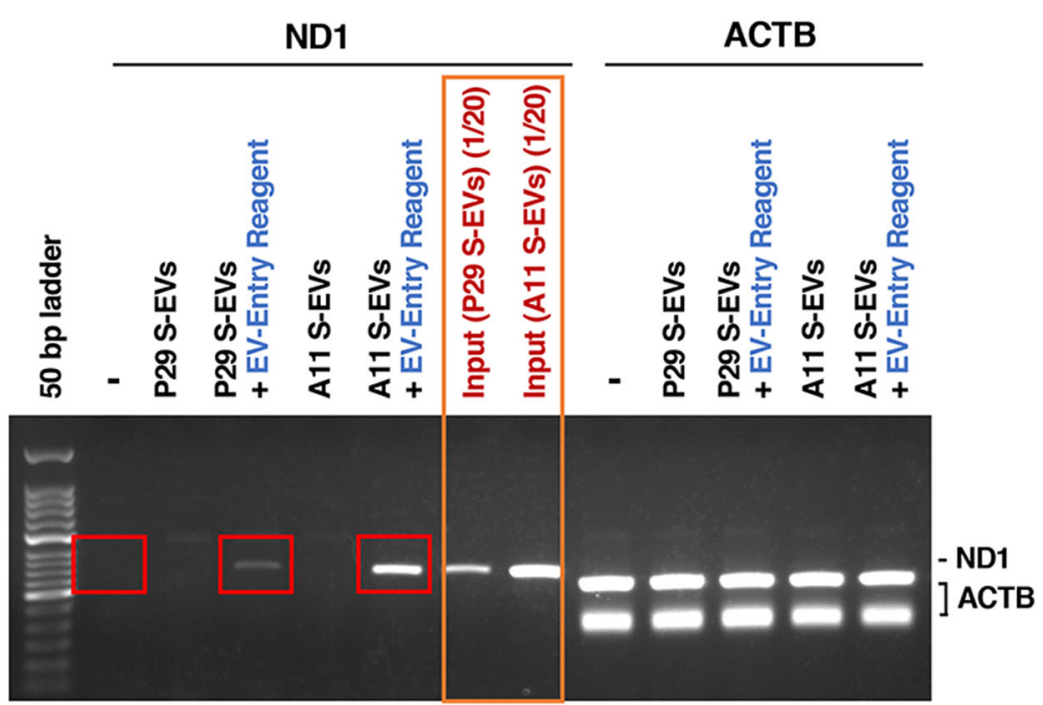

Fig. 8 S-EV-mediated mtDNA transfer to $\rho^{0} P 29$ cells. (a) Schematic drawing of the procedure of S-EV-mediated transfer of mtDNA. S-EVs isolated from the conditioned media of P29 and A11 cells were incubated with $\rho^{0}$ P29 cells in the presence or absence of EV-Entry reagent for 2 days. The cells were detached from the dishes by trypsinization and washed extensively with PBS. (b) PCR analysis of mtDNA transfer to $\rho^{0} \mathrm{P} 29$ cells via SEVs. S-EVs-exposed $\rho^{0} P 29$ cell DNAs were isolated and subjected to PCR amplification of the ND1 and ACTB genes. The PCR primers for ACTB gave rise to two bands. As inputs, one-twentieth of the amount of S-EVs added to $\rho^{0} \mathrm{P} 29$ cells was also subjected to PCR analysis

supplemented with $10 \%$ FBS and $40 \mu \mathrm{g} / \mathrm{ml}$ gentamicin in a humidified atmosphere with $95 \%$ air $/ 5 \% \mathrm{CO}_{2}$ at $37^{\circ} \mathrm{C}$. CTLL-2 cells, a mouse cytotoxic T-cell line (RCB0637, RIKEN BioResource Research Center), were cultured in DMEM supplemented with $10 \% \mathrm{FBS}$ and $50 \mathrm{ng} / \mathrm{ml} \mathrm{re-}$ combinant mouse IL-2 (BioLegend, San Diego, CA, USA). Human cervical cancer HeLa cells, human lung carcinoma A549 cells, human colon carcinoma DLD1 cells and human pancreatic carcinoma MIAPaCa-2 cells [39] were cultured in DMEM/10\% FBS. MtDNA-less P29 ( $\rho^{0}$ P29) cells [1] and $\rho^{0}$ HeLa cells (EB8 cells) [40] were cultured in DMEM supplemented with $0.1 \mathrm{mg} / \mathrm{ml}$ sodium pyruvate and $0.5 \mathrm{mg} / \mathrm{ml}$ uridine. Mouse embryonic fibroblasts (MEFs) were prepared and cultivated as described previously [41]. The addition of EVs to $\rho^{0}$ P29 cells and $\rho^{0} \mathrm{HeLa}$ cells was performed in the presence or absence of the EV-Entry System (System Biosciences,
Palo Alto, CA, USA), which increases the rate of EV uptake and offloading of the cargo into the cytoplasm of the recipient cells.

\section{Labeling of mitochondria}

For in vitro experiments, the cells and EVs were labeled with MTDR or mtGFP and MitoTracker Red, respectively. For in vivo experiments, cells were stained with MitoB LT Red, which is designed for mitochondrial retention for long-term visualization and shows stronger fluorescence signals than other commercially available dyes (Dojindo). Staining of the cells was performed according to the manufacturer's instructions. The cells were observed under a Leica TSC SP8 confocal laser scanning microscope (Leica Microsystems, Wetzlar, Germany). 
a
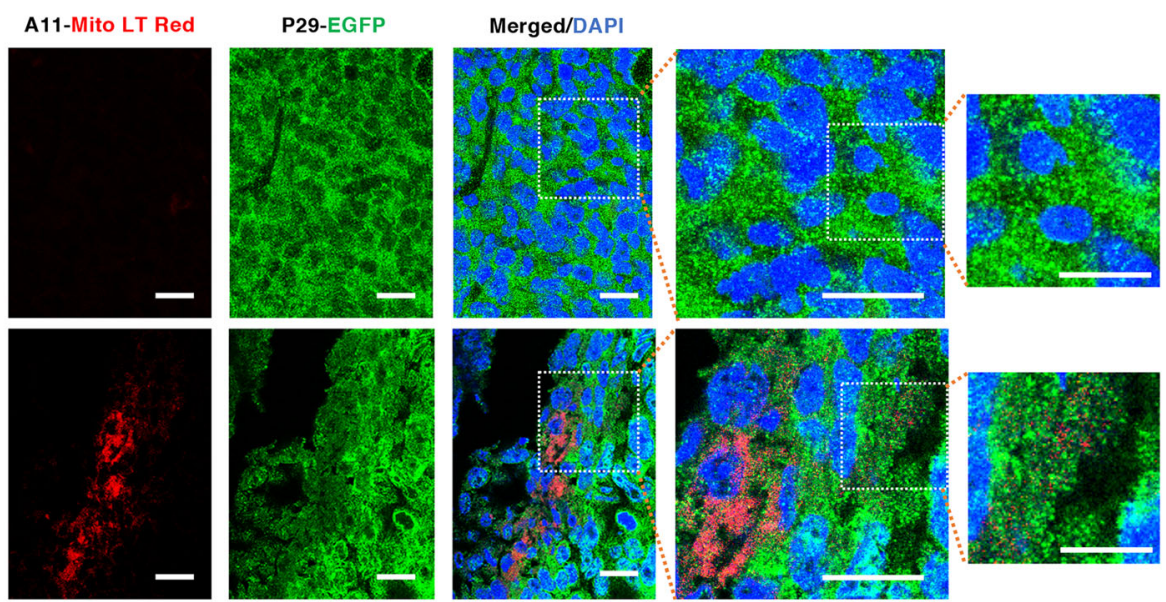

b
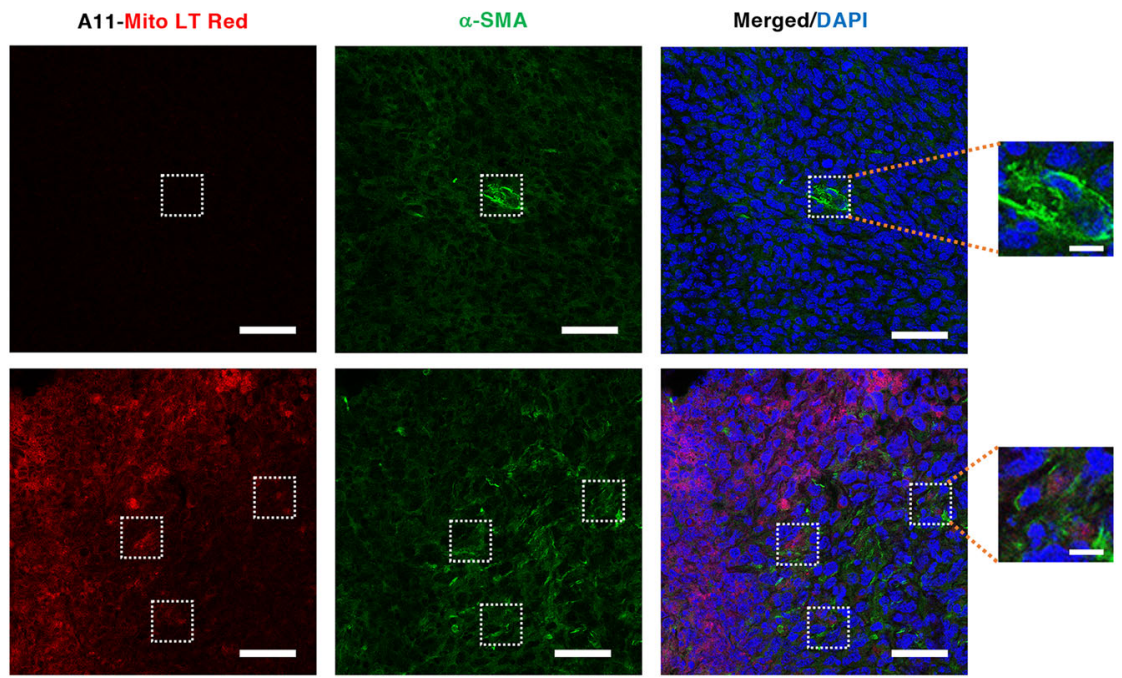

Fig. 9 Diffusion of mitochondria-related vesicles of A11 cells in the homograft tumor microenvironment. (a) Transfer of mitochondria-related vesicles from MitoB LT Red-labeled A11 cells (A11-Mito LT Red) to P29-EGFP cells in a syngeneic tumor model. Upper panels. Area without A11MitoB LT Red cells. Lower panels. Area with A11-MitoB LT Red cells. Note that red-colored vesicles diffused from A11-MitoB LT Red cells toward the upper right and localized within EGFP-P29 cells in the area surrounded by a dotted line. Scale bars: $10 \mu \mathrm{m}$ and $20 \mu \mathrm{m}$ for the rightmost panels and other panels, respectively. (b) Transfer of mitochondria-related vesicles from mitochondria of MitoB LT Red-labeled A11 cells (A11MitoB LT Red) to CAFs. Upper panels. Area without A11-MitoB LT Red cells. Lower panels. Area with A11-Mito LT Red cells. Note that red-colored vesicles were released from A11-Mito LT Red cells and localized within a-SMA-positive CAFs in the areas surrounded by a dotted line. Scale bars: $10 \mu \mathrm{m}$ and $50 \mu \mathrm{m}$ for the rightmost panels and other panels, respectively

\section{Coculture}

A11-MTDR or P29-MTDR cells $\left(5 \times 10^{4}\right.$ cells $)$ and P29mtGFP, A11-mtGFP cells $\left(5 \times 10^{4}\right.$ cells $)$, respectively, were cocultured on glass coverslips in a well of a 12-well multiwell culture plate for $24 \mathrm{~h}$. In other experiments, A11-MTDR cells $\left(5 \times 10^{4}\right.$ cells $)$ were cocultured with EGFP-P29 cells $\left(5 \times 10^{4}\right.$ cells $)$ WA-mFib-mtGFP cells $\left(5 \times 10^{4}\right.$ cells), RAW264.7-mtGFP cells or MEF-mtGFP $\left(5 \times 10^{4}\right.$ cells $)$ for $24 \mathrm{~h}$. The cells were fixed with $4 \%$ paraformaldehyde and observed under a confocal laser microscope. A11-MTDR cells $\left(5 \times 10^{4}\right.$ cells $)$ were also cocultured with CTLL-2-mtGFP cells $\left(1 \times 10^{5}\right.$ cells $)$ in a $35-\mathrm{mm}$ glass-bottom culture dish for $24 \mathrm{~h}$ and observed under a confocal laser microscope without fixation.

\section{Preparation of EVs from cell culture media and normal mouse serum}

EVs in cell culture medium were isolated by ultracentrifugation [42] with some modifications. Briefly, cells were cultured in DMEM containing 10\% exosome-free FBS 
for 2 or 3 days. Exosome-free FBS was prepared by ultracentrifugation at $110,000 \times \mathrm{g}$ overnight at $4{ }^{\circ} \mathrm{C}$. The conditioned medium was centrifuged at $400 \times \mathrm{g}$ for $10 \mathrm{~min}$ to remove cells, and the supernatant was centrifuged at $2000 \times \mathrm{g}$ for $20 \mathrm{~min}$ to remove cell debris and apoptotic bodies. The resulting supernatant was ultracentrifuged at $15,000 \times \mathrm{g}$ for $30 \mathrm{~min}$ at $4{ }^{\circ} \mathrm{C}$; the pellet was washed with Dulbecco's phosphate buffered saline (DPBS) and used as large EVs (L-EVs). The supernatant was passed through a Millex-GP filter $(0.22 \mu \mathrm{m}$ pore) (Merck-Millipore Burlington, MA, USA) and ultracentrifuged at $110,000 \times \mathrm{g}$ for $90 \mathrm{~min}$ at $4{ }^{\circ} \mathrm{C}$. The pellet was washed with DPBS to eliminate contaminated proteins and centrifuged again at $110,000 \times \mathrm{g}$ for $90 \mathrm{~min}$ at $4{ }^{\circ} \mathrm{C}$. The pellet was resuspended in DPBS and used as small EVs (SEVs); EVs were sterilized by filtration through a MillexGV filter $(0.22 \mu \mathrm{m}$ pore). EVs in C57BL/6 mouse serum were isolated using Total Exosome Isolation Reagent (from serum) (Thermo Fisher Scientific).

\section{Characterization of isolated S-EVs}

The size range of the isolated S-EVs from the culture media of A11 cells was measured by a Zeta Potential/ Particle Size Analyzer (Otsuka Electronics, Osaka, Japan). Annexin A1, CD9, CD63, CD81, GAPDH, LC3B, $\beta$-actin, Lamin $\mathrm{A} / \mathrm{C}$ and mitochondrial proteins were detected by Western blot analyses using rabbit polyclonal anti-Annexin A1 antibody (Cell signaling Technology, Danvers, MA, USA), rabbit polyclonal anti-CD9 antibody (Flarebio Biotech LLC, Baltimore, MD, USA), rabbit polyclonal anti-CD63 antibody (Flarebio Biotech LLC), rabbit polyclonal anti-CD81 antibody (Cell signaling Technology), rabbit monoclonal anti-GAPDH antibody (Cell signaling Technology), rabbit polyclonal antiLC3B antibody (Cell signaling Technology), mouse monoclonal anti- $\beta$-actin (Santa Cruz Biotechnology, Dallas, TX, USA), mouse monoclonal anti-Lamin A/C antibody (Santa Cruz Biotechnology) and Membrane Integrity WB Antibody Cocktail (abcam, Cambridge, UK). For this, EVs were dissolved in SDS-sample buffer, and the particle concentration was adjusted based on the protein concentration measured by the $\mathrm{BCA}$ method using bovine serum albumin (BSA) as a standard. For preparation of cell lysates of P29 and A11 cells, they were lysed in RIPA buffer containing cOmplete Protease Inhibitor Cocktail (Merck, Kenilworth, NJ, USA) and PhosSTOP (Merck Millipore, Billerica, MA, USA). The lysates were centrifuged at $10,000 \times \mathrm{g}$ for $10 \mathrm{~min}$ at $4{ }^{\circ} \mathrm{C}$, and the supernatants were used for immunoblot analysis. A11 mitochondria were isolated by using Mitochondria Isolation Kit for Cultured Cells (abcam). After SDSpolyacrylamide gel electrophoresis, the proteins were transferred to an Immobilon-P transfer membrane (Merck Millipore, Billerica, MA, USA). The membrane was incubated with washed with TBS-T (5 mM Tris/ $13.8 \mathrm{mM} \mathrm{NaCl} / 0.05 \%$ Tween-20), and then incubated with horseradish peroxidase (HRP)-conjugated goat antirabbit IgG or goat anti-mouse IgG. Proteins were detected using ECL Plus Western blotting detection reagent (Amersham Biosciences, Piscataway, NJ, USA). For staining of EVs with PKH67, isolated L-EVs and S-EVs were stained using PKH67 Fluorescence Cell Linker Kits (Sigma-Aldrich, St. Louis, MO, USA) for $5 \mathrm{~min}$, resuspended in DPBS, and centrifuged again at $15,000 \times \mathrm{g}$ for $30 \mathrm{~min}$ and $110,000 \times \mathrm{g}$ for $90 \mathrm{~min}$, respectively, at $4{ }^{\circ} \mathrm{C}$. The pellet was resuspended in DPBS.

\section{Transmission electron microscopy (TEM)}

Negative-stain TEM and cryo-TEM of A11 S-EVs were performed by JEOL Ltd. (Tokyo, Japan).

\section{Detection of mtDNA in EVs and $\rho^{0}$ cells by polymerase chain reaction (PCR)}

For detection of mtDNA in EVs, the EVs were dissolved in $20 \mathrm{mM} \mathrm{NaOH}$, incubated for $10 \mathrm{~min}$ at $95^{\circ} \mathrm{C}$, neutralized with $1 \mathrm{M}$ Tris- $\mathrm{HCl}$ ( $\mathrm{pH} 8.0$ ), and then subjected to PCR analysis. For detection in mtDNA in $\rho^{0} \mathrm{P} 29$ cells, the cells were detached from culture dishes with trypsinEDTA (Sigma-Aldrich, Co., LLC, Saint Louis, MO, USA) at $37^{\circ} \mathrm{C}$ for $10 \mathrm{~min}$, washed extensively with DPBS three times, and then dissolved in DirectPCR Lysis Reagent (Cell) (Viagen Biotech, Inc., Los Angeles, CA, USA) containing $0.2 \mathrm{mg} / \mathrm{ml}$ proteinase $\mathrm{K}$. After incubation at $55^{\circ} \mathrm{C}$ for $60 \mathrm{~min}$ with shaking, proteinase $\mathrm{K}$ was inactivated by heating at $85^{\circ} \mathrm{C}$ for $45 \mathrm{~min}$. PCR was performed using GoTaq Hot Start DNA polymerase (Promega Corp., Madison, WI, USA). The PCR conditions were $94{ }^{\circ} \mathrm{C}$ for $5 \mathrm{~min}$ followed by 32 cycles of $94^{\circ} \mathrm{C}$ for $30 \mathrm{~s}$, $58^{\circ} \mathrm{C}$ for $30 \mathrm{~s}$, and $72^{\circ} \mathrm{C}$ for $30 \mathrm{~s}$. The primers used were $5^{\prime}$-CCGGGCCCATTAAACTTGGG-3' and 5' - TAGT GTTTTTGGGGTTTGGCATT-3' for $H V R, 5^{\prime}$-CTAG CAGAAACAAACCGGGC-3' and $5^{\prime}$-ATGGTGGTAC TCCCGCTGTA-3' for ND1, 5'-GACTTGCAACCCTA CACGGA $-3^{\prime}$ and $5^{\prime}$-TGTGGTGTAAGCATCTGG GT-3' for COI, 5'-ACCACTAACCTGACTATCAAGC C-3' and 5' 'GTTTGGTTCCCTCATCGGGT-3' for ND4, 5'-GTTGGTTGTCTTGGGTTAGCAT-3" and 5'-CTACCCCAATCCCTCCTTCCA-3' for ND6, and $5^{\prime}$-CTCTGGCTCCTAGCACCATGAAGA-3' and $5^{\prime}$ GTAAAACGCAGCTCAGTAACAGTCCG-3' for $A C T$ $B$. Aliquots of the PCR products were electrophoresed in $1.5 \%$ agarose gels and visualized on a transilluminator after staining with ethidium bromide. For recognition of the G13997A mutation by PCR-RFLP, a 254 bp fragment containing the $13,997 \mathrm{G}>\mathrm{A}$ site was amplified by PCR using the mismatched primers forward primer: $5^{\prime}$ CCCACTAACAATTAAACCTAAACCTCCATActTA-

3 ', (small letters indicate the mismatch site) and reverse 
primer: 5'-GGGGCAGGTAGGTCAATGAA-3' to create a restriction site for AflII [1]. After digestion with AflII, the restriction fragments (223 bp and $31 \mathrm{bp}$ ) were separated in a $3 \%$ agarose gel. For detection of mtDNA in EVs from human cancer cells, the following primers were used: 5' - TCTTTCATGGGGAAGCAGAT-3' and 5' - GCACTCTTGTGCGGGATATT-3' for HVR, 5'TCATGACCCTTGGCCATAAT-3' and 5' - GGGGAA TGCTGGAGATTGTA-3' for ND1, 5' - ACGTTGTA GCCCACTTCCAC-3' and 5'- GGGTTCTTCGAATG TGTGGT-3' for COI, 5' -TGAACGCAGGCACATACT TC-3' and 5' $^{\prime}$-TGTTTGTCGTAGGCAGATG-3' for ND4, and $5^{\prime}$ - CCCCGAGCAATCTCAATTAC-3' and 5'-GGTGTGGTCGGGTGTGTTAT-3' for ND6. For the detection of mtDNA in $\rho^{0} \mathrm{HeLa}$ cells, the following primers were used: $5^{\prime}$ - GTTGGTTGTCTTGGGTTAGC AT-3' and 5' - CTACCCCAATCCCTCCTTCCA-3' for ND6, and $5^{\prime}$-TGACGGGGTCACCCACACTGTGCCCA TCTA-3' and 5' - CTAGAAGCATTTGCGGTGGACG ATGGAGGG-3' for ACTB.

\section{Animal experiments}

Five- to six-week-old male C57BL/6 J mice (CLEA Japan, Osaka, Japan) were used in this study. The mice were housed in a barrier facility under specific pathogen-free conditions and assessed with regard to health every day. For the in vivo mitochondrial distribution in tumor tissues, syngeneic transplantable P29 cells or EGFP-P29 cells $\left(1 \times 10^{6}\right.$ cells $)$ were subcutaneously implanted into the mice. When the tumor size reached approximately $0.75 \mathrm{~cm}^{3}$, another syngeneic A11 cell line $\left(5 \times 10^{6}\right.$ cells) labeled with MitoB LT Red was injected intratumorally. After 3 days, homograft tumors were excised and immediately embedded and frozen in OCT compound for subsequent analysis. The mice were euthanized by $\mathrm{CO}_{2}$ inhalation at the end of the study.

\section{Immunostaining}

Cryostat sections $(7 \mu \mathrm{m}$ thick) of homograft tumor tissues containing EGFP-P29 and MitoB LT Red-labeled A11 cells were fixed with $4 \%$ paraformaldehyde and stained with rabbit polyclonal anti-GFP antibody (Proteintech, Sankt Leon-Rot, Germany) followed by Alexa Fluor 488 (AF488)-conjugated anti-rabbit IgG. In this case, to clearly visualize EGFP-P29 cells, immunostaining with anti-GFP antibody was employed. Cryostat sections of tumor tissues containing P29 and MitoB LT Red-labeled A11 cells were fixed with 4\% paraformaldehyde for 10 min and blocked with 1\% BSA in DPBS. The sections were treated with an M. O. M. Immunodetection Kit (Vector Laboratories, Burlingame, CA, USA) and then incubated with mouse monoclonal anti- $\alpha$-SMA (clone 1A4) (Dako, Jena, Germany) antibody followed by AF488-conjugated goat anti-mouse IgG. The sections were counterstained with DAPI and observed under a Leica TSC SP8 confocal laser scanning microscope. WA-mFib cells were also immunostained with the anti$\alpha$-SMA antibody followed by AF594-conjugated goat anti-mouse IgG.

\begin{abstract}
Abbreviations
ACTB: $\beta$-Actin; AF: Alexa Fluor; a-SMA: a-Smooth muscle actin; BSA: Bovine serum albumin; CAF: Cancer-associated fibroblast; DMEM: Dulbecco's modified Eagle's medium; DPBS: Dulbecco's phosphate-buffered saline; EGFP: Enhanced green fluorescent protein; EV: Extracellular vesicle; FBS: Fetal bovine serum; HVR: D-loop hypervariable region; L-EVs: Large extracellular vesicles; MEF: Mouse embryonic fibroblast; MitoB LT Red: MitoBright LT Red; mtDNA: Mitochondrial DNA; mtGFP: CellLight mitochondria-GFP;

MTDR: MitoTracker Deep Red; NSCLC: Non-small cell lung carcinoma; ND: NADH dehydrogenase subunit; PCR: Polymerase chain reaction; RFLP: Restriction fragment length polymorphism; S-EVs: Small extracellular vesicles; TAM: Tumor-associated macrophage; TEM: Transmission electron microscopy; TNT: Tunneling nanotube
\end{abstract}

\section{Supplementary Information}

The online version contains supplementary material available at https://doi. org/10.1186/s12860-021-00391-5.

Additional file 1 Fig. S1. Intercellular transfer of mitochondria-related vesicles between A11 and P29 cells. mtGFP-labeled P29 cells (P29-mtGFP) and MTDR-labeled A11 cells (A11-MTDR) were cocultured for $24 \mathrm{~h}$. Scale bars: $20 \mu \mathrm{m}$. Fig. S2. Intercellular transfer of mitochondria-related vesicles between A11 cells and MEF cells. MTDR-labeled A11 cells (A11-MTDR) and mtGFP-labeled MEF cells (MEF-mtGFP) were cocultured for $24 \mathrm{~h}$. Scale bars: $20 \mu \mathrm{m}$. Fig. S3. Red- and green-colored mitochondria-related vesicles in the coculture of A11-MTDR and P29-mtGFP, WA-mFib-mtGFP or RAW264.7-mtGFP. Note that red- and green-colored mitochondriarelated vesicles exist in the areas where no cells are present. Scale bars: $30 \mu \mathrm{m}$. Fig. S4. PCR analysis of the presence of mtDNA in S-EVs isolated from various human cancer cell lines. S-EVs were isolated from the conditioned medium of HeLa cells, A549 cells, DLD1 cells and MIAPaCa-2 cells and subjected to PCR amplification of various mtDNA genes. Fig. S5. Incorporation of A11 S-EVs into P29 cells. S-EVs isolated from the conditioned media of A11-MTDR cells were stained with PKH67, resulting in red and green two-colored PKH-67-positive S-EVs. They were then added to P29 cells and incubated for $24 \mathrm{~h}$. Note that two-colored S-EVs are within P29 cells. Scale bars: 20 mm. Fig. S6. S-EV-mediated mtDNA transfer to $\rho^{0}$ HeLa cells. S-EVs isolated from the conditioned media of HeLa cells were incubated with $\rho^{0} \mathrm{HeLa}$ cells in the presence or absence of EVEntry reagent for 2 days. The cells were detached from the dishes by trypsinization and washed extensively with PBS. DNA was isolated and then subjected to PCR amplification of ND1 and ACTB ( $\beta$-actin). The primers for ND1 were the same as those described in Fig. S4. The primers for ACTB were used as a loading control. As an input, one-twentieth of the amount of S-EVs added to $\rho^{0}$ HeLa cells was also subjected to PCR analysis. Fig. S7. Full-size images of Western blots. Fig. S8. Full-size images of Western blots. The yellow dotted line indicates the cropped region.

\section{Acknowledgments}

Not applicable.

\section{Authors' contributions}

$\mathrm{KT}$ conceived and performed the research, analyzed the data, and wrote the paper; NK performed the IHC study. HN supervised the research. All authors read and approved the final manuscript.

\section{Funding}

This work was supported in part by JSPS KAKENHI (grant no. 19 K07654 to K. Takenaga and grant nos. JP26290060, 17H03602, JP16H01579 and JP2OH03540 to H. Nagase) and AMED (grant no. 18ae0101051, 21zf0127001h0001 and 21ek0109495h0001 to H. Nagase). 


\section{Availability of data and materials}

All data generated or analyzed during this study are included in this published article and its Additional files.

\section{Declarations}

\section{Ethics approval and consent to participate}

All animal handling and experimental procedures were performed in compliance with the institutional guidelines for the care and use of animals in research and the ARRIVE guideline (https://arriveguidelines.org). The protocol was approved by the Committee on the Ethics of Animal Experiments of Chiba Cancer Center (Permission Number: 18-1).

\section{Consent for publication}

Not applicable.

\section{Competing interests}

The authors declare that they have no competing interests.

Received: 22 March 2021 Accepted: 20 September 2021 Published online: 07 October 2021

\section{References}

1. Ishikawa K, Takenaga K, Akimoto M, Koshikawa N, Yamaguchi A, Imanishi H, et al. ROS-generating mitochondrial DNA mutations can regulate tumor cell metastasis. Science. 2008:320:661-4. https://doi.org/10.1126/science.1156906.

2. Koshikawa N, Akimoto M, Hayashi II, Nagase H, Takenaga K. Association of predicted pathogenic mutations in mitochondrial ND genes with distant metastasis in NSCLC and colon cancer. Sci Rep. 2017;7(1):15535. https://doi. org/10.1038/s41598-017-15592-2.

3. Kulawiec M, Owens KM, Singh KK. mtDNA G10398A variant in AfricanAmerican women with breast cancer provides resistance to apoptosis and promotes metastasis in mice. J Hum Genet. 2009;54:647-54. https://doi. org/10.1038/jhg.2009.89.

4. Kulawiec M, Owens KM, Singh KK. Cancer cell mitochondria confer apoptosis resistance and promote metastasis. Cancer Biol Ther. 2009;8:137885. https://doi.org/10.4161/cbt.8.14.8751.

5. Arnold RS, Sun CQ, Richards JC, Grigoriev G, Coleman IM, Nelson PS, et al. Mitochondrial DNA mutation stimulates prostate cancer growth in bone stromal environment. Prostate. 2009;69:1-11. https://doi.org/10.1002/pros.2 0854.

6. Arnold RS, Fedewa SA, Goodman M, Osunkoya AO, Kissick HT, Morrissey C, True LD, Petros JA. Bone metastasis in prostate cancer: Recurring mitochondrial DNA mutation reveals selective pressure exerted by the bone microenvironment. Bone. 2015;78:81-86. Bone. 2015;78:81-86. doi: https:// doi.org/10.1016/.j.bone.2015.04.046.

7. Nunes JB, Peixoto J, Soares P, Maximo V, Carvalho S, Pinho SS, et al. OXPHOS dysfunction regulates integrin- $\beta 1$ modifications and enhances cell motility and migration. Hum Mol Genet. 2015;24:1977-90. https://doi.org/1 0.1093/hmg/ddu612.

8. Lin YH, Chu YD, Lim SN, Chen CW, Yeh CT, Lin WR. Impact of an MT-RNR1 gene polymorphism on hepatocellular carcinoma progression and clinical characteristics. Int J Mol Sci. 2021;22(3):1119. https://doi.org/10.3390/ijms22 031119.

9. Takasu M, Tada Y, Wang JO, Tagawa M, Takenaga K. Resistance to apoptosis induced by microenvironmental stresses is correlated with metastatic potential in Lewis lung carcinoma. Clin Exp Metastasis. 1999;17:409-16. https://doi.org/10.1023/a:1006632819086.

10. Sumi C, Okamoto A, Tanaka H, Nishi K, Kusunoki M, Shoji T, et al. Propofol induces a metabolic switch to glycolysis and cell death in a mitochondrial electron transport chain-dependent manner. PLoS One. 2018;13(2): e0192796. https://doi.org/10.1371/journal.pone.0192796.

11. Pérez-Amado CJ, Tovar H, Gómez-Romero L, Beltrán-Anaya FO, Bautista-Piña V, Dominguez-Reyes C, et al. Mitochondrial DNA mutation analysis in breast cancer: shifting from germline heteroplasmy toward homoplasmy in tumors. Front Oncol. 2020;10:572954. https://doi.org/10.3389/fonc.2020.572954.

12. Gasparre G, lommarini L, Porcelli AM, Lang M, Ferri GG, Kurelac I, Zuntini R, Mariani E, Pennisi LF, Pasquini E, Pasquinelli G, Ghelli A, Bonora E, Ceccarell C, Rugolo M, Salfi N, Romeo G, Carelli V. An inherited mitochondrial DNA disruptive mutation shifts to homoplasmy in oncocytic tumor cells. Hum Mutat. 2009;30:391-396. doi: https://doi.org/10.1002/humu.20870.
13. Yin C, Li DY, Guo X, Cao HY, Chen YB, Zhou F, et al. NGS-based profiling reveals a critical contributing role of somatic D-loop mtDNA mutations in HBV-related hepatocarcinogenesis. Ann Oncol. 2019;30:953-62. https://doi. org/10.1093/annonc/mdz105.

14. Coller HA, Khrapko K, Bodyak ND, Nekhaeva E, Herrero-Jimenez P, Thilly WG. High frequency of homoplasmic mitochondrial DNA mutations in human tumors can be explained without selection. Nat Genet. 2001;28:147-50. https://doi.org/10.1038/88859.

15. Fliss MS, Usadel H, Caballero OL, Wu L, Buta MR, Eleff SM, et al. Facile detection of mitochondrial DNA mutations in tumors and bodily fluids. Science. 2000; 287(5460):2017-9. https://doi.org/10.1126/science.287.5460.2017.

16. Liu D, Dong Z, Wang J, Tao Y, Sun $X$, Yao X. The existence and function of mitochondrial component in extracellular vesicles. Mitochondrion. 2020;54: 122-7. https://doi.org/10.1016/j.mito.2020.08.005.

17. Herst PM, Dawson RH, Berridge MV. Intercellular communication in tumor biology: a role for mitochondrial transfer. Front Oncol. 2018;8:344. https:// doi.org/10.3389/fonc.2018.00344

18. Sahinbegovic H, Jelinek T, Hrdinka M, Bago JR, Turi M, Sevcikova T, et al. Intercellular mitochondrial transfer in the tumor microenvironment. Cancers (Basel). 2020;12:1787. https://doi.org/10.3390/cancers12071787.

19. van Niel G, D'Angelo G, Raposo G. Shedding light on the cell biology of extracellular vesicles. Nat Rev Mol Cell Biol. 2018;19:213-28. https://doi.org/1 0.1038/nrm.2017.125.

20. Jeppesen DK, Fenix AM, Franklin JL, Higginbotham JN, Zhang Q, Zimmerman LJ, et al. Reassessment of exosome composition. Cell. 2019;177: 428-445.e18. https://doi.org/10.1016/j.cell.2019.02.029.

21. D'Acunzo P, Pérez-González R, Kim Y, Hargash T, Miller C, Alldred MJ, et al. Mitovesicles are a novel population of extracellular vesicles of mitochondria origin altered in Down syndrome. Sci Adv. 2021;7:eabe5085. https://doi. org/10.1126/sciadv.abe5085.

22. Rustom A, Saffrich R, Markovic I, Walther P, Gerdes HH. Nanotubular highways for intercellular organelle transport. Science. 2004;303:1007-10. https://doi.org/10.1126/science.1093133.

23. Lou E. A ticket to ride: the implications of direct intercellular communication via tunneling nanotubes in peritoneal and other invasive malignancies. Front Oncol. 2020;10:559548. https://doi.org/10.3389/fonc.202 0.559548 .

24. Pickles $S$, Vigié $P$, Youle RJ. Mitophagy and quality control mechanisms in mitochondrial maintenance. Curr Biol. 2018;28:R170-85. https://doi.org/10.1 016/j.cub.2018.01.004.

25. Catalano M, O'Driscoll L. Inhibiting extracellular vesicles formation and release: a review of EV inhibitors. J Extracell Vesicles. 2019;9(1):1703244. https://doi.org/10.1080/20013078.2019.1703244.

26. Datta A, Kim H, McGee L, Johnson AE, Talwar S, Marugan J, et al. Highthroughput screening identified selective inhibitors of exosome biogenesis and secretion: a drug repurposing strategy for advanced cancer. Sci Rep. 2018:8(1):8161. https://doi.org/10.1038/s41598-018-26411-7.

27. Baixauli F, López-Otín C, Mittelbrunn M. Exosomes and autophagy: coordinated mechanisms for the maintenance of cellular fitness. Front Immunol. 2014;5:403. https://doi.org/10.3389/fimmu.2014.00403.

28. Picca A, Guerra F, Calvani R, Coelho-Junior HJ, Bossola M, Landi F, et al. Generation and release of mitochondrial-derived vesicles in health, aging and disease. J Clin Med. 2020;9(5):1440. https://doi.org/10.3390/ jcm9051440.

29. Nicolás-Ávila JA, Lechuga-Vieco AV, Esteban-Martínez L, Sánchez-Díaz M, Díaz-García E, Santiago DJ, et al. A network of macrophages supports mitochondrial homeostasis in the heart. Cell. 2020;183:94-109.e23. https:// doi.org/10.1016/j.cell.2020.08.031.

30. Choong CJ, Okuno T, Ikenaka K, Baba K, Hayakawa H, Koike M, et al. Alternative mitochondrial quality control mediated by extracellular release. Autophagy. 2020:1-13. https://doi.org/10.1080/15548627.2020.1848130.

31. Buratta S, Tancini B, Sagini K, Delo F, Chiaradia E, Urbanelli L, et al. Lysosomal exocytosis, exosome release and secretory autophagy: the autophagic- and endo-lysosomal systems go extracellular. Int J Mol Sci. 2020;21 (7):2576. https://doi.org/10.3390/ijms21072576.

32. Craven L, Alston CL, Taylor RW, Turnbull DM. Recent advances in mitochondrial disease. Annu Rev Genomics Hum Genet. 2017;18:257-75. https://doi.org/10.1146/annurev-genom-091416-035426.

33. Roy A, Bera S. CAF cellular glycolysis: Linking cancer cells with the microenvironment. Tumor Biol. 2016:37:8503-14. https://doi.org/10.1007/ s13277-016-5049-3. 
34. Ron-Harel N, Notarangelo G, Ghergurovich JM, Paulo JA, Sage PT, Santos D, et al. Defective respiration and one-carbon metabolism contribute to impaired naïve T cell activation in aged mice. Proc Natl Acad Sci U S A. 2018:115:13347-52. https://doi.org/10.1073/pnas.1804149115.

35. Ron-Harel N, Sharpe AH, Haigis MC. Mitochondrial metabolism in T cell activation and senescence: a mini-review. Gerontology. 2016;61:131-8. https://doi.org/10.1159/000362502.

36. Willms E, Cabañas C, Mäger I, Wood MJA, Vader P. Extracellular vesicle heterogeneity: subpopulations, isolation techniques, and diverse functions in cancer progression. Front Immunol. 2018;9:738. https://doi.org/10.3389/ fimmu.2018.00738.

37. Kauppila TES, Kauppila JHK, Larsson NG. Mammalian mitochondria and aging: An update. Cell Metab. 2017;25:57-71. https://doi.org/10.1016/j. cmet.2016.09.017.

38. Akimoto M, Maruyama R, Takamaru H, Ochiya T, Takenaga K. Soluble IL-33 receptor SST2 inhibits colorectal cancer malignant growth by modifying the tumor microenvironment. Nat Commun. 2016;7(1):13589. https://doi.org/1 0.1038/ncomms 13589

39. Akimoto M, lizuka M, Kanematsu R, Yoshida M, Takenaga K. Anticancer effect of ginger extract against pancreatic cancer cells mainly through reactive oxygen species-mediated autotic cell death. PLoS One. 2015;10(5): e0126605. https://doi.org/10.1371/journal.pone.0126605.

40. Enomoto N, Koshikawa N, Gassmann M, Hayashi J, Takenaga K. Hypoxic induction of hypoxia-inducible factor-1alpha and oxygen-regulated gene expression in mitochondrial DNA-depleted HeLa cells. Biochem Biophys Res Commun. 2002:297(2):346-52. https://doi.org/10.1016/S0006-291X(02)02186-1.

41. Jozefczuk J, Drews K, Adjaye J. Preparation of mouse embryonic fibroblast cells suitable for culturing human embryonic and induced pluripotent stem cells. J Vis Exp. 2012;64(64):e3854. https://doi.org/10.3791/3854.

42. Lobb RJ, Becker M, Wen SW, Wong CS, Wiegmans AP, Leimgruber A, et al. Optimized exosome isolation protocol for cell culture supernatant and human plasma. J Extracell Vesicles. 2015;4(1):27031. https://doi.org/10.3402/ jev.v4.27031.

\section{Publisher's Note}

Springer Nature remains neutral with regard to jurisdictional claims in published maps and institutional affiliations.

Ready to submit your research? Choose BMC and benefit from:

- fast, convenient online submission

- thorough peer review by experienced researchers in your field

- rapid publication on acceptance

- support for research data, including large and complex data types

- gold Open Access which fosters wider collaboration and increased citations

- maximum visibility for your research: over $100 \mathrm{M}$ website views per year

At BMC, research is always in progress.

Learn more biomedcentral.com/submissions 